\title{
Photocatalytic removal of Malachite green dye from aqueous solutions by nano-composites containing titanium dioxide: $\mathrm{A}$ systematic review
}

\author{
Soheila Amiri-Hosseini ${ }^{(\mathbb{D}}$, Yalda Hashempour ${ }^{*(\mathbb{D})}$ \\ Department of Environmental Health Engineering, School of Public Health, Mazandaran University of Medical Sciences, Sari, Iran
}

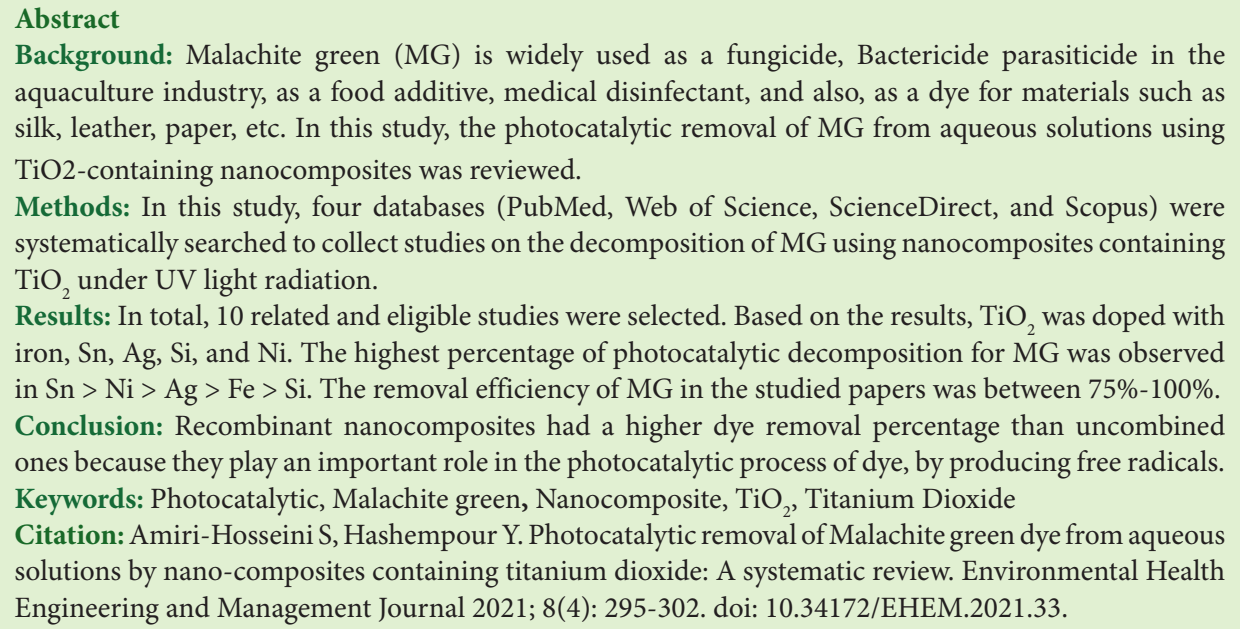

Article History:

Received: 18 April 2021

Accepted: 20 June 2021

ePublished: 22 November 2021

\section{Introduction}

Organic pollutants in industrial water and wastewater are considered as a significant problem for people around the world. The textile and wastewater industries containing dyes are one of the main sources of pollutants, which are sometimes discharged directly as water effluent into the environment (1). Organic dyes as chemicals are commonly used in many industries such as food, textile, cosmetics, etc. If these dyes enter the environment as wastewater without any treatment, they can be very harmful to humans, aquatic microorganisms, and the environment $(2,3)$. Among the industries, the textile industry is considered as one of the largest industries consuming water with the production of colored wastewater (4). The textile industry contains organic dyes that are biodegradable and stable and have a high resistance to biodegradation, which is considered as a problem of surface water pollution (5-7). Dyes are divided into different types based on their chemical composition and application. Based on the dyes' chemical structure, they are categorized into 20 to 30 groups, the most significant of which are azo, anthraquinone, and phthalocyanine $(8,9)$. Malachite green $(\mathrm{MG})$ with the chemical formula $\mathrm{C}_{52} \mathrm{H}_{54} \mathrm{~N}_{4} \mathrm{O}_{12}$ is one of the cationic organic dyes that have a high solubility in water (2). MG is applied in many industries such as dyeing silk, plastic, hemp, linen, pharmaceuticals, and printing, and due to its easy preparation and low manufacturing cost, its use is very high (10-12). It is used in aquaculture industries for disease control and fish parasites as an antifungal and antiseptic agent, antimicrobial in food and aquaculture industries. MG toxicity is naturally high and its toxicity increases with increasing temperature, concentration, and $\mathrm{pH}(2,11)$. When MG enters the food chain, it causes carcinogenic, teratogenic, and mutagenesis effects, respiratory toxicity, reduced human and chromosomal fertility, and chromosome adhesion $(13,14)$. In humans, the ingestion of MG may irritate the gastrointestinal tract. Skin contact with MG causes skin irritation, redness and pain $(15,16)$. Therefore, the removal of MG from the output of fish farming systems or the sewage of textile industries, paper making, etc. is necessary to prevent its adverse effects on aquatic organisms (17). Because dyes are non-degradable molecules, treatment of colored wastewater is difficult. For this reason, various techniques 
including coagulation, flocculation, advanced oxidation, precipitation, ozonation, aerobic digestion, anaerobic, adsorption, membrane purification, membrane filtration, ion exchange, and optical decomposition are used. The above-mentioned techniques have advantages and limitations. But today, researchers are increasingly using efficient methods, which are economically sustainable technologies for treating colored effluents (18-20). Today, the photocatalyst process is used as a simple and efficient method to remove organic pollutants and dyes from industrial effluents and has been shown to play a significant role in environmental control by decomposing organic pollutants (21-23). The photocatalytic technique is superior to traditional purification techniques. Its characteristics include stability, cost-effectiveness, highly photoactive, fast oxidation, high oxidation of pollutants even at low concentrations, no formation of polycyclic products, etc. This process generates free radicals such as hydroxyl radicals $\left(\mathrm{OH}^{\circ}\right)$, which is a very efficient oxidant for organic matter pollutants $(5,24)$. The photocatalytic process with nanocomposites as methods for removing organic dyes from industrial effluents has helped researchers to produce new nanocomposite particles with different composite samples such as organic biopolymers and inorganic salts. Ion exchangers, photocatalysts, etc., operate (24). Titanium dioxide $\left(\mathrm{TiO}_{2}\right)$ itself is one of the most extensively used metal oxides with high photocatalytic activity without the formation of secondary pollutants $(25,26)$. Three well-known crystal structures for $\mathrm{TiO}_{2}$ are known as anatase, tarantula, and brookite. The anatase phase has more photocatalytic activity than rutile and brookite due to having the highest level of activity $(27,28)$. There is a controversial debate about the effectiveness of nanocomposites containing $\mathrm{TiO}_{2}$ in removal of $\mathrm{MG}$ from aqueous environments. Hence, to evaluate the effectiveness of the nanocomposites, this study aimed to systematically review all experimental studies related to this subject.

\section{Materials and Methods \\ Search strategy}

Systematically searches have been done in databases including PubMed, Web of Science, ScienceDirect, and Scopus between January 2007 and September 2020 to investigate the photocatalytic removal of $\mathrm{MG}$ by nanocomposites containing $\mathrm{TiO}_{2}$ according to the PRISMA guidelines. For this purpose, searches were performed according to Medical Subject Headings (MeSH) with the keywords of "Malachite green" AND ("Photocatalytical" OR "decomposition") AND ("Aqueous" OR "wastewater" OR “water") AND ("Nanocomposites" OR "halloysite" OR “ $\mathrm{TiO}_{2}$ ”).

\section{Inclusion criteria and data extraction}

Articles were selected given they provided original data on the subject. Review papers, conference papers, book chapters, protocols, dissertations, and data with photocatalysts based on various types of nanocomposites other than $\mathrm{TiO}_{2}$ were excluded. The inclusion criteria were English full-text of articles, focusing on the photocatalytic removal of MG using nanocomposite synthesized with $\mathrm{TiO}_{2}$.

Extracted information available for each study include the name of the first author, place of the study, year of the publication, and information on other variables. The information including $\mathrm{pH}$, reaction contact time, nanocomposite dose, initial concentration of MG dye, if available, was noted and recorded.

\section{Results}

The systematic search identified 91 articles in four databases. In the first step, 12 papers out of 91 obtained papers were excluded due to duplication via EndNote X7 software (Thomson Reuters, Canada). Also, 22 articles were excluded due to the lack of entry criteria in the title and abstract screening. Moreover, 47 articles were removed based on the full-text screening. So, 10 articles were eligible and used in the present systematic review, as illustrated in Figure 1.

Table 1 illustrates the main results of the included articles. Among the selected articles, six articles used metal elements along with $\mathrm{TiO}_{2}$. One article used $\mathrm{Fe}$ (29), two articles used tin (Sn) in two different ways $(30,31)$, one article used Ag (29), and the remaining article used nickel (Ni) $(32,33)$. The highest percentage of photocatalytic decomposition for MG was observed in $\mathrm{Sn}>\mathrm{Ni}>\mathrm{Ag}$ $>\mathrm{Fe}>\mathrm{Si}$. The remaining 5 articles out of 10 articles, comparing other nanocomposites that used commercial compounds with $\mathrm{TiO}_{2}$ (34-38). The highest MG removal efficiency (100\%) was found in the study of Tayade et al that examined anatase nanocrystalline combined with $\mathrm{TiO}_{2}$ (the initial MG concentration of $50 \mathrm{mg} \cdot \mathrm{L}^{-1}$, and reaction time of 40 minutes) (36). The lowest MG removal efficiency (75\%) was found in the study of Yang et al that examined $\mathrm{SiO}_{2} @ \mathrm{TiO}_{2}$ composite nanosheets (the initial MG concentration of $50 \mathrm{mg} . \mathrm{L}^{-1}$, and reaction time of 90 minutes) (35).

\section{Discussion}

The role of iron metal in the performance of $\mathrm{TiO}_{2}$ nanocomposites

In a study on the removal of $\mathrm{MG}$ dye (the initial concentration of $2.5 \mathrm{mg} . \mathrm{L}^{-1}$ ), with the help of $\mathrm{TiO}_{2}$ and iron metal with different amounts of metal under UV irradiation, it was concluded that undoped $\mathrm{TiO}_{2}\left(\mathrm{UTiO}_{2}\right)$ under UV irradiation had 75\% removal efficiency. While $0.3 \mathrm{FeTiO}_{2}$ and $7 \mathrm{FeTiO}_{2}$ had $81 \%$ and $73 \%$ removal efficiency, respectively (irradiation time was 110 minutes). All $\mathrm{Fe}^{3+}$ in the $0.3 \mathrm{FeTiO}_{2}$ catalyst is trapped in the $\mathrm{TiO}_{2}$ crystal lattice, while in the case of the $7 \mathrm{FeTiO}_{2}$ catalyst, 


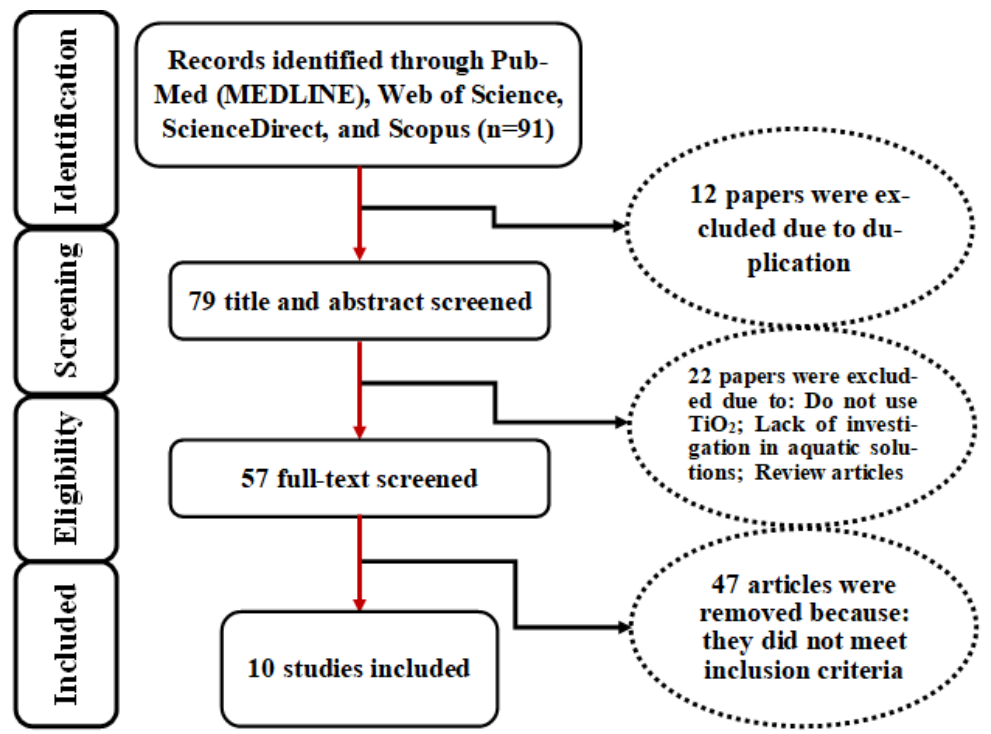

Figure 1. Preferred reporting items for systematic reviews and meta-analysis (PRISMA) flow diagram of database search evidence and inclusion criteria.

it contained iron oxide in addition to $\mathrm{Fe}^{3+}$ ions and that doping with $\mathrm{Fe}^{3+}$ ions reduced particle size, which decreases the surface area (29). If the dye concentration increases to $5 \mathrm{mg}$. $\mathrm{L}^{-1}$, the removal efficiency increases slightly. In this situation, it was found that $\mathrm{UTiO}_{2}$ is less effective because it has the smallest surface area. The higher the level of surface area, the higher the photocatalytic performance because it absorbs more photons and dye molecules, and the electrons oxidize the $\mathrm{O}^{2-}$ anions by reducing $\mathrm{Ti}(\mathrm{IV})$ to $\mathrm{Ti}(\mathrm{III})$. The oxygen atoms return and in one place, it creates a void, then, the dye molecules occupy the oxygen void and form hydroxyl groups that tend to be adsorbed on the hydrophilic surface. Because the irradiated surface is almost super-hydrophobic, it absorbs hydroxyl groups and forms active hydroxyl radicals, which play an important role in photocatalytic activity. Another reason for the increase in the removal of $0.3 \mathrm{FeTiO}_{2}$ compared to $7 \mathrm{FeTiO}_{2}$ is that the first catalyst shows the highest peak value with the help of the XRD test in the titanium anatase phase, but in the $7 \mathrm{FeTiO}_{2}$ catalyst, it is shown that the anatase phase peak is reduced or eliminated. The crystalline phase of anatase itself increases the contact surface by reducing the particle size. $\mathrm{Fe}^{3+}$ acts as a mediator in doping and causes the transfer of produced electrons and increases the production of free radicals (29). Because the irradiated surface is almost superhydrophobic, it absorbs hydroxyl groups and forms active hydroxyl radicals, which play an important role in the photocatalytic activity, according to the following reactions:

$$
\begin{aligned}
& \mathrm{TiO}_{2}+\mathrm{hv} \rightarrow \mathrm{e}^{-}+\mathrm{h}^{+} \\
& \mathrm{Fe}^{3+}+\mathrm{h}^{+} \rightarrow \mathrm{Fe}^{4+} \\
& \mathrm{Fe}^{3+}+\mathrm{e}^{-} \rightarrow \mathrm{Fe}^{2+}
\end{aligned}
$$

$$
\begin{aligned}
& \mathrm{Fe}^{2+}+\mathrm{O}_{2}(\mathrm{ads}) \rightarrow \mathrm{Fe}^{3+}+\mathrm{O}^{2-} \\
& \mathrm{Fe}^{2+}+\mathrm{Ti}^{4+} \rightarrow \mathrm{Fe}^{3+}+\mathrm{Ti}^{3+} \\
& \mathrm{Ti}^{3+} \mathrm{O}_{2}(\mathrm{ads}) \rightarrow \mathrm{Ti}^{4+}+\mathrm{O}_{2}^{-} \\
& \mathrm{Fe}^{4+}+\mathrm{OH}^{-}(\text {ads }) \rightarrow \mathrm{Fe}^{3+}+\mathrm{OH}^{0}(\text { ads })
\end{aligned}
$$

The role of tungstophosphoric acid in the performance of $\mathrm{TiO}_{2}$ nanocomposites

Rengifo-Herrera et al examined the $\mathrm{TiO}_{2}-$ tungstophosphoric acid (TPA) at different ratios $(20 \%$ and $30 \% \mathrm{w} / \mathrm{w}$ ) (34). The results revealed that under UVA, the MG solutions were well bleached through the oxidative procedure of $\mathrm{N}$-demethylation being the $\mathrm{TiO}_{2}$ powder containing $30 \%$ (w/w) of TPA (100\% of bleaching in 60 minutes). Experiments performed using blue-light irradiation under $\mathrm{N}_{2}$ atmosphere displayed that $\mathrm{TiO}_{2}$ powders containing TPA were not able to bleach the MG solutions.

TPA plays an important role in this process because this unchanged compound is known as a heteropoly compound that is an efficient electron trap, and other reasons for the increase in $\mathrm{TiO}_{2}-\mathrm{TPA}-30 \%$ photocatalytic activity compared to $\mathrm{TiO}_{2}-\mathrm{TPA}-20 \%$ and $\mathrm{TiO}_{2}-\mathrm{TPA}-0 \%$ is that the dye molecules on its surface are closer to the titanium surface and simply allow oxidative degradation hydroxyl radicals attached to the surface (34).

The role of $\mathrm{Sn}$ metal in the performance of $\mathrm{TiO}_{2}$ nanocomposites

Sayllkan et al, reported that where $\mathrm{TiO}_{2}$ was prepared in single and double layers on a glass surface and Sn metal was doped on it, the experiments showed that the higher the number of layers, the higher the percentage of removal 


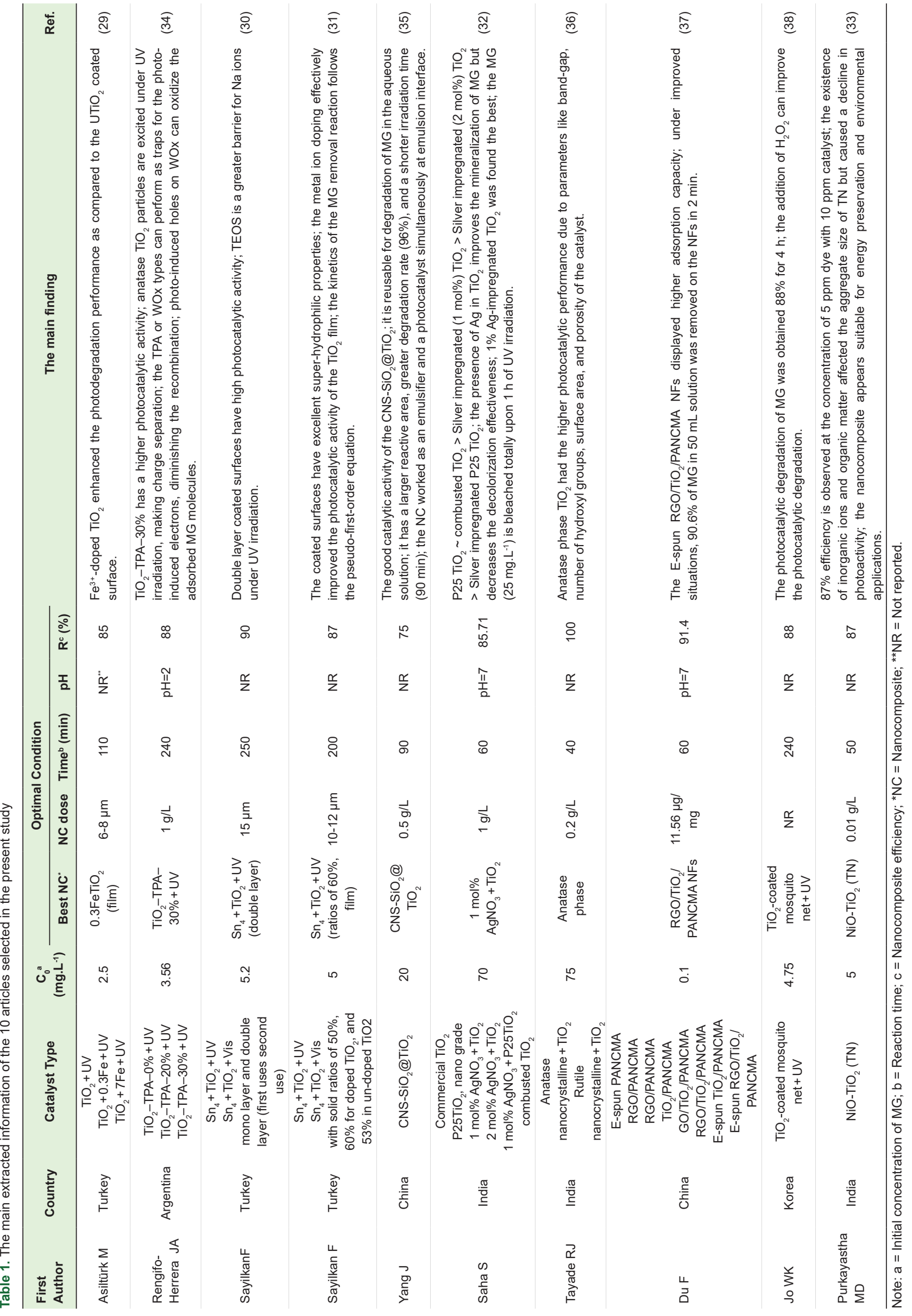


due to the higher amount of Sn (30). Controlling particle size and increasing the contact surface, and improving electron transfer efficiency enhances photocatalytic efficiency. Sn ions may be substituted for titanium to form the solid compound $\mathrm{Ti}_{1}-\mathrm{Sn}_{\mathrm{x}} \mathrm{O}_{2}$, which due to its high photocatalytic performance, tends to degrade MG more.

Sayllkan et al (31) used Sn-doped and un-doped $\mathrm{TiO}_{2}$ nanoparticles at three solid ratios 50\%, 60\% in doped $\mathrm{TiO}_{2}$, and $53 \%$ in un-doped $\mathrm{TiO}_{2}$. The highest removal percentage was observed at solid ratio of $60 \%$. By increasing the solid ratio, the electrons oxidize the $\mathrm{O}^{2-}$ anion holes by reducing the $\mathrm{Ti}(\mathrm{IV})$ to $\mathrm{Ti}(\mathrm{III})$ and the oxygen atoms return and create a void. The dye molecules then occupy the oxygen void, forming hydroxyl groups that tend to be adsorbed on the hydrophilic surface. As the irradiated surface is almost super-hydrophilic, it absorbs hydroxyl groups and forms active hydroxyl radicals, which play an important role in photocatalytic activity. Another reason was the high reaction rate, which has led to an increase in its photocatalytic activity. Reasons for increasing the percentage of decomposed $\mathrm{TiO}_{2}$ doped with $\mathrm{Sn}$ compared to non-doped $\mathrm{TiO}_{2}$ are high micropore surface area, crystal size, and micropore volume, but for non-doped $\mathrm{TiO}_{2}$, the surface area and average diameter of adsorption pores are smaller. Doped with $\mathrm{Sn}, \mathrm{Sn}^{4+}$ is present in the reaction medium, which by controlling the particle size (by reducing it increases the surface area) and the crystal size of the oxides and reducing the size of the powder, causes the powder to take a spherical shape. Interestingly, in Sn-doped $\mathrm{TiO}_{2}$, the crystal size and particle size are smaller than those in non-doped $\mathrm{TiO}_{2}$. Doped $\mathrm{Sn}^{4+}$ also improves the transfer efficiency of electrons from the LUMO Malachite band to the conduction band of Sn doped with $\mathrm{TiO}_{2}$. These electrons oxidize $\mathrm{O}^{2-}$ anionic holes and oxygen atoms by reducing $\mathrm{Ti}(\mathrm{IV})$ to $\mathrm{Ti}(\mathrm{III})$. It returns and creates a void. Then, the dye molecules occupy the oxygen void and form hydroxyl groups that tend to be adsorbed on the hydrophilic surface. And form active hydroxyl radicals that play an important role in photocatalytic activity. It was revealed that $\mathrm{Sn}$ doped with $\mathrm{TiO}_{2}$ is capable of absorbing UV light and can be used for irradiated photocatalytic applications.

The role of $\mathrm{SiO}_{2} @ \mathrm{TiO}_{2}$ nanosheets in the performance of $\mathrm{TiO}_{2}$ nanocomposites

Yang et al (35) used $\mathrm{CNS}-\mathrm{SiO}_{2} @ \mathrm{TiO}_{2}$ composite nanosheets for photocatalytic decomposition of $\mathrm{MG}$ dye. This study revealed that the nanosheet has effective catalytic performance and reusability in photocatalytic degradation of MG in aqueous solution, decomposition rate higher than $96 \%$ in less than 90 minutes. The reason for its high efficiency is its high contact surface, which can have good potential in wastewater treatment. The rate of decomposition of MG increased with exposure to UV radiation, but without the addition of $\mathrm{CNS}-\mathrm{SiO}_{2} @ \mathrm{TiO}_{2}$, the amount of decomposition was very low and only $8 \%$ after 80 minutes of irradiation. The decomposition rate was enhanced by increasing the decomposition time due to $\mathrm{N}$-demethylation and emulsification process, which caused the effective contact surface between the substrate and the catalyst, but as experiments show, with increasing time and the MG concentration from a certain value, the efficiency of MG photocatalytic analysis by $\mathrm{CNS}-\mathrm{SiO}_{2} @$ $\mathrm{TiO}_{2}$ decreases because the MG molecules adsorbed on the surface of the catalyst cause less oxygen to reach the catalyst and this reduces the decomposition efficiency (35).

The role of $\mathrm{AgNO}_{3}$ in the performance of $\mathrm{TiO}_{2}$ nanocomposites

Saha et al (32) used TO (Commercial $\left.\mathrm{TiO}_{2}\right)$, PTO (P25 $\mathrm{TiO}_{2}$, nano grade), STO(I) (1 mol\% $\left.\mathrm{AgNO}_{3}+\mathrm{TO}\right), \mathrm{STO}(\mathrm{II})$ (2 mol\% $\mathrm{AgNO}_{3}+\mathrm{TO}$ ), SPTO (1 mol\% $\mathrm{AgNO}_{3}+\mathrm{PTO}$ ), and CTO (combusted $\mathrm{TiO}_{2}$ ). The highest removal percentage of $\mathrm{MG}$ is related to commercial P25 TiO, PTO (92\%), and subsequent further decomposition was obtained by the combustion of $\mathrm{TiO}_{2}$, CTO (90\%). STO (I) has a higher percentage of decomposition (85\%) than STO (II) $(74 \%)$ due to higher UV screening before reaching $\mathrm{TiO}_{2}$ level if present in STO (II). A comparison of SPTO and PTO showed that the amount of decomposition of the first one $(60 \%)$ is lower than the second one (92\%) and this is due to the presence of silver in SPTO, which causes a catalytic reduction, and the surface may have decreased due to saturation with a silver (32).

The role of anatase and rutile phases in the performance of $\mathrm{TiO}_{2}$ nanocomposites

Tayade et al (36) examined anatase and rutile phases of titanium to remove MG. Their results revealed that anatase type has a higher photocatalytic activity. The highest decomposition (100\%) was obtained in an experiment with the rutile phase for MG for 3 hours under UV irradiation, but the same result was obtained with the help of the anatase phase for 1 hour. One of the reasons for the great photocatalytic performance of the anatase phase is the surface area $\left(124 \mathrm{~m}^{2} \cdot \mathrm{g}^{-1}\right.$ and the pores are $7.5 \mathrm{~nm})$ as compared to the rutile phase $\left(2 \mathrm{~m}^{2} \cdot \mathrm{g}^{-1}\right.$ and the diameter is $5.4 \mathrm{~nm}$ ). The photocatalytic activity is extremely dependent on the hydroxyl group on the surface that attacks contaminants in water. High surface area is also useful for accommodating more groups of hydroxyl. Another reason for the superiority of anatase over rutile is the increase in band gap in the pairs of electron holes (36).

The role of graphene oxide in the performance of $\mathrm{TiO}_{2}$ nanocomposites

$\mathrm{Du}$ et al (37) used the composite nanofibers of graphene oxide, $\mathrm{TiO}_{2}$ for effective adsorption and photocatalytic removal of MG. Decomposition percent of MG by E-spun 
RGO/TiO $/$ PANCMA NFs was obtained 90.6\%. However, by adsorption on NFs for 60 minutes under UV irradiation, the amount of dye decomposition for 2 minutes was $91.4 \%$. The reason for the increased performance of E-spun RGO/ $\mathrm{TiO}_{2} / \mathrm{PANCMA}$ NFs compared to E-spun $\mathrm{TiO}_{2} / \mathrm{PANCMA}$ and $\mathrm{GO} / \mathrm{TiO}_{2} / \mathrm{PANCMA} \mathrm{NFs}$ was its high current density, which was itself a factor in separating pairs of electron holes. Another reason is that the charge transfer rate between the surfaces of the E-spun $\mathrm{RGO} / \mathrm{TiO}_{2}$ / PANCMA NFs was faster and produced more electrons, resulting in better photocatalytic activity; spun is RGO/ $\mathrm{TiO}_{2} /$ PANCMA NFs because the effects of $\mathrm{pH}$ through protonation in solution affect the form of malachite and have a clear effect on dye adsorption. Because under acidic conditions it produced protons $\left(\mathrm{H}^{+}\right)$that combined with $\mathrm{O}_{2}$ in solution to produce $\mathrm{H}_{2} \mathrm{O}_{2}$ and irradiated with the same hydrogen peroxide, producing hydroxyl radicals that acted as a powerful oxidant in photocatalytic action (37).

\section{The role of mosquito net in the performance of $\mathrm{TiO}_{2}$} nanocomposites

Jo and Tayade (38) experimented $\mathrm{TiO}_{2}$ on a mosquito net to decompose MG under UV light. For 4 hours, the decomposition percentage of $88 \%$ was achieved. Factors affecting high photocatalytic efficiency with the help of $\mathrm{TiO}_{2}$ include the release of photocatalytic nanoparticles in the refined solution, electronic properties and photocatalytic structure, phase composition, band gap, the surface area play an effective role in the ability of the photocatalyst. When the $\mathrm{TiO}_{2}$ photocatalyst is irradiated, light with energy equal to or higher than the energy of the band gap is excited by absorbing the light of the electron band. Water or organic contaminants absorbed on the $\mathrm{TiO}_{2}$ surface react with the charge transfer. The reaction of $\mathrm{H}^{+}$with $\mathrm{OH}^{-}$or $\mathrm{H}_{2} \mathrm{O}$ results in the formation of hydroxyl$\mathrm{OH}$ radicals, each of which are strong oxidants that attack the desired undesirable organic pollutants. The production of oxygen peroxide during the reaction is a powerful oxidant that plays an important role in the photocatalytic degradation of dyes, and this oxygen peroxide increases the concentration of hydroxyl radicals (38).

\section{The role of nickel metal (Ni) in the performance of $\mathrm{TiO}_{2}$} nanocomposites

In the study of Purkayastha et al (33), nanocomposites containing $\mathrm{TiO}_{2}$ and nickel metal (Ni) were used. The results showed that the best photocatalytic efficiency (87\%) was observed at the optimum concentration of $5 \mathrm{ppm}$ with 10 ppm of catalyst. Separation of charge carriers and their transfer at the nanocomposite junction is where these carriers are produced in the reaction solution and $\mathrm{NiO}$ is transferred to the $\mathrm{TiO}_{2}$ conduction band, and this process causes oxygen uptake and production of superoxide $\left(\mathrm{O}^{2}\right)$ radicals, which play an active role in photocatalytic activity. Experiments have shown that increasing the dye concentration reduces the decomposition process but increasing the catalyst causes a significant increase in the dye due to the presence of active sites on the titanium surface to absorb the dye, which reduces the activation energy for dye degradation (33).

The role of environmental factors ( $\mathrm{pH}$, reaction time, initial concentration, catalyst dose)

$\mathrm{pH}$ can affect the surface charge of photocatalyst and adsorption capacity (3,14-16). Tan et al (20) and Gupta et al (11) discussed the effect of $\mathrm{pH}$ on the attractive or repulsive force of nanocomposites. Generally, at high $\mathrm{pH}$, due to the negative surface of the nanocomposite, it favors the absorption of cations and an electrostatic attraction is created. But at acidic $\mathrm{pH}$, the surface of the nanocomposite, due to protonation, becomes positively charged and favors the adsorption of anions. Moreover, the production of hydroxyl radicals is high in the alkaline range. Electrons oxidize oxygen molecules to produce peroxide radicals. This radical, combined with ambient hydrogen, produces hydroxyl radicals that play an important role in photocatalytic activity (23).

The longer the time, the more color molecules are in contact with the nanocomposite and the more interaction between the dye and the nanocomposite is provided and the more production opportunities are provided for free radicals (37).

With increasing catalyst dose in the removal process, a decreasing trend was observed. The reason for this trend is that with increasing the activity level of the catalyst, the bleaching increases to a certain amount because at higher amounts, the suspended particles of the catalyst prevent the passage of ultraviolet light and cause more light scattering. Therefore, a further increase in the amount of catalyst does not affect the efficiency of photocatalytic decomposition $(20,25)$.

With increasing dye concentration, the dye removal efficiency increased to a certain extent and further increase of dye concentration led to a decrease in removal efficiency. The removal rate depends on the formation of free radicals at the catalyst surface and the probability of reaction with the dye molecules. The reason for the decrease in decolorization due to the increase in dye concentration is that the active sites on the catalyst surface are covered by dye molecules and the production of hydroxyl radicals is reduced. Another reason that can be mentioned is that at high concentrations of dye, a large amount of UV is absorbed by the dye molecule instead of being absorbed by the nanocomposite particles, and the catalyst efficiency decreases due to the radical reduction of hydroxyl and peroxide (32,35).

In this review study, the number of articles for each type of nanocomposite was less than two articles, therefore, it was not possible to perform a meta-analysis (39). Because 
all other synthesis techniques are less transparent and/ or are less likely to be valid. There are some gaps in this field of study conducting such research on real samples, and performing the process on the effluent of $\mathrm{MG}$ on biological organisms such as Daphnia. Moreover, in this study, only photocatalytic processes that use UV light were analyzed. The effect of this process can be examined with other lights such as visible or sunlight.

\section{Conclusion}

There is a notorious debate about the effectiveness of nanocomposites containing $\mathrm{TiO}_{2}$ in the removal of $\mathrm{MG}$ from aqueous environments. Therefore, investigation of the photocatalytic activity of the nanocomposites is of great importance. Hence, in the present systematic review, a total of 10 relevant and suitable studies were collected. According to the findings of the reviewed studies, $\mathrm{TiO}_{2}$ was doped with iron, Sn, Ag, Si, and Ni. The highest percentage of photocatalytic decomposition for MG was observed in $\mathrm{Sn}>\mathrm{Ni}>\mathrm{Ag}>\mathrm{Fe}>\mathrm{Si}(90,87,85.71,85$, and $75 \%$, respectively). Based on these results, it is necessary to take into account some parameters such as initial MG concentration, irradiation time, catalysts dose, $\mathrm{pH}$, etc., to improve photocatalytic efficiency. Increasing the dye concentration reduces the decomposition process, but increasing the catalyst causes a significant increase in the dye due to the presence of active sites on the titanium surface to absorb the dye, which reduces the activation energy to degrade the dye. Finally, it is noteworthy that recombinant nanocomposites had a higher dye removal percentage than uncombined ones because they perform an important role in the photocatalytic process. By producing free radicals, they play a more effective role in the photocatalytic process of dye.

\section{Acknowledgments}

The authors would like to thank the Mazandaran University of Medical Sciences, for providing financial support (Ethical code: IR.MAZUMS.REC.1399.6843).

\section{Ethical issues}

The authors hereby certify that all the data collected during the research are expressed in the manuscript, and no data from the study has been or will be published elsewhere separately.

\section{Competing interests}

The authors declare that there is no conflict of interests.

\section{Authors' contributions}

All authors were involved in the study design, data collection and analysis, and manuscript preparation. The final version of the manuscript was reviewed and confirmed by both authors.

\section{References}

1. Jafari H, Afshar S. Improved photodegradation of organic contaminants using nano- $\mathrm{TiO} 2$ and $\mathrm{TiO} 2-\mathrm{SiO} 2$ deposited on portland cement concrete blocks. Photochem Photobiol 2016; 92(1): 87-101. doi: 10.1111/php.12554.

2. Ghaedi M, Azad FN, Dashtian K, Hajati S, Goudarzi A, Soylak M. Central composite design and genetic algorithm applied for the optimization of ultrasonic-assisted removal of malachite green by $\mathrm{ZnO}$ Nanorod-loaded activated carbon. Spectrochim Acta A Mol Biomol Spectrosc 2016; 167: 157-64. doi: 10.1016/j.saa.2016.05.025.

3. Zarrabi M, Haghighi M, Alizadeh R, Mahboob S. Solarlight-driven photodegradation of organic dyes on sonodispersed $\mathrm{ZnO}$ nanoparticles over graphene oxide: Sono vs. conventional catalyst design. Separation and Purification Technology 2019; 211: 738-52. doi: 10.1016/j. seppur.2018.10.026.

4. Moussavi G, Mahmoudi M. Removal of azo and anthraquinone reactive dyes from industrial wastewaters using MgO nanoparticles. J Hazard Mater 2009; 168(2-3): 806-12. doi: 10.1016/j.jhazmat.2009.02.097.

5. Bansal J, Hafiz AK, Sharma SN. Photoreduction of dye with noble metal gold permeated with metal oxide titania. J Nanosci Nanotechnol 2020; 20(6): 3896-901. doi: 10.1166/ jnn.2020.17501.

6. Modwi A, Abbo MA, Hassan EA, Al-Duaij OK, Houas A. Adsorption kinetics and photocatalytic degradation of malachite green $(\mathrm{MG})$ via $\mathrm{Cu} / \mathrm{ZnO}$ nanocomposites. J Environ Chem Eng 2017; 5(6): 5954-60. doi: 10.1016/j. jece.2017.11.024.

7. Kurczewska J, Cegłowski M, Schroeder G. Alginate/ PAMAM dendrimer - Halloysite beads for removal of cationic and anionic dyes. Int J Biol Macromol 2019; 123: 398-408. doi: 10.1016/j.ijbiomac.2018.11.119.

8. dos Santos AB, Cervantes FJ, van Lier JB. Review paper on current technologies for decolourisation of textile wastewaters: perspectives for anaerobic biotechnology. Bioresour Technol 2007; 98(12): 2369-85. doi: 10.1016/j. biortech.2006.11.013.

9. Nidheesh PV, Gandhimathi R, Ramesh ST. Degradation of dyes from aqueous solution by Fenton processes: a review. Environ Sci Pollut Res Int 2013; 20(4): 2099-132. doi: 10.1007/s11356-012-1385-z.

10. Ghorbani F, Molavi H, Fathi S, Piri F. Application of response surface methodology to optimize malachite green removal by $\mathrm{Cl}$-nZVI nanocomposites. Journal of Water and Wastewater 2017; 28(4): 79-92. doi: 10.22093/ WWJ.2017.44300. [In Persian].

11. Gupta K, Khatri OP. Reduced graphene oxide as an effective adsorbent for removal of malachite green dye: plausible adsorption pathways. J Colloid Interface Sci 2017; 501: 1121. doi: 10.1016/j.jcis.2017.04.035.

12. Vergis BR, Krishna RH, Kottam N, Nagabhushana BM, Sharath R, Darukaprasad B. Removal of malachite green from aqueous solution by magnetic $\mathrm{CuFe}_{2} \mathrm{O}_{4}$ nanoadsorbent synthesized by one pot solution combustion method. J Nanostructure Chem 2018; 8: 1-12. doi: 10.1007/ s40097-017-0249.

13. Baek MH, Ijagbemi CO, O SJ, Kim DS. Removal of Malachite Green from aqueous solution using degreased coffee bean. J Hazard Mater 2010; 176(1-3): 820-8. doi: 10.1016/j.jhazmat.2009.11.110.

14. Sacara AM, Cristea C, Muresan LM. Electrochemical 
detection of Malachite Green using glassy carbon electrodes modified with $\mathrm{CeO}_{2}$ nanoparticles and Nafion. Journal of Electroanalytical Chemistry 2017; 792: 23-30. doi: 10.1016/j.jelechem.2017.03.030.

15. Kiani G, Dostali M, Rostami A, Khataee AR. Adsorption studies on the removal of Malachite Green from aqueous solutions onto halloysite nanotubes. Applied Clay Science 2011; 54(1): 34-9. doi: 10.1016/j.clay.2011.07.008.

16. Rajabi HR, Khani O, Shamsipur M, Vatanpour V. Highperformance pure and $\mathrm{Fe} 3+$-ion doped $\mathrm{ZnS}$ quantum dots as green nanophotocatalysts for the removal of malachite green under UV-light irradiation. J Hazard Mater 2013; 250-251: 370-8. doi: 10.1016/j.jhazmat.2013.02.007.

17. Yong L, Zhanqi G, Yuefei J, Xiaobin H, Cheng S, Shaogui $\mathrm{Y}$, et al. Photodegradation of malachite green under simulated and natural irradiation: kinetics, products, and pathways. J Hazard Mater 2015; 285: 127-36. doi: 10.1016/j. jhazmat.2014.11.041.

18. Khatri J, Nidheesh PV, Singh TA, Kumar MS. Advanced oxidation processes based on zero-valent aluminium for treating textile wastewater. Chem Eng J 2018; 348: 67-73. doi: 10.1016/j.cej.2018.04.074.

19. Dawood S, Sen TK, Phan C. Synthesis and characterisation of novel-activated carbon from waste biomass pine cone and its application in the removal of congo red dye from aqueous solution by adsorption. Water Air Soil Pollut 2014; 225: 1818. doi: 10.1007/s11270-013-1818-4.

20. Tan KA, Morad N, Teng TT, Norli I, Panneerselvam P. Removal of cationic dye by magnetic nanoparticle $\left(\mathrm{Fe}_{3} \mathrm{O}_{4}\right)$ impregnated onto activated maize cob powder and kinetic study of dye waste adsorption. APCBEE Procedia 2012; 1: 83-9. doi: 10.1016/j.apcbee.2012.03.015.

21. Alibeigi AN, Javid N, Amiri Gharaghani M, Honarmandrad Z, Parsaie F. Synthesis, characteristics, and photocatalytic activity of zinc oxide nanoparticles stabilized on the stone surface for degradation of metronidazole from aqueous solution. Environ Health Eng Manag 2021; 8(1): 55-63. doi: 10.34172/EHEM.2021.08.

22. Ebrahimi A, Jafari N, Ebrahimpour K, Nikoonahad A, Mohammadi A, Fanaei F, et al. The performance of $\mathrm{TiO}_{2} /$ NaY-zeolite nanocomposite in photocatalytic degradation of Microcystin-LR from aqueous solutions: Optimization by response surface methodology (RSM). Environ Health Eng Manag 2020; 7(4): 245-56. doi: 10.34172/EHEM.2020.29.

23. Rangkooy HA, Jahani F, Siahi Ahangar A. Photocatalytic removal of xylene as a pollutant in the air using $\mathrm{ZnO}$ activated carbon, $\mathrm{TiO} 2$-activated carbon, and $\mathrm{TiO} 2 /$ ZnOactivated carbon nanocomposites. Environ Health Eng Manag 2020; 7(1): 41-7. doi: 10.34172/EHEM.2020.06.

24. Gupta VK, Sharma G, Pathania D, Kothiyal N. Nanocomposite pectin $\mathrm{Zr}$ (IV) selenotungstophosphate for adsorptional/photocatalytic remediation of methylene blue and malachite green dyes from aqueous system. J Ind Eng Chem 2015; 21: 957-64. doi: 10.1016/j.jiec.2014.05.001.

25. Zheng P, Du Y, Chang PR, Ma X. Amylose-halloysite$\mathrm{TiO}_{2}$ composites: preparation, characterization and photodegradation. Appl Surf Sci 2015; 329: 256-61. doi: 10.1016/j.apsusc.2014.12.158.

26. Gilja V, Katančić Z, Krehula LK, Mandić V, Hrnjak-Murgić $\mathrm{Z}$. Efficiency of $\mathrm{TiO}_{2}$ catalyst supported by modified waste fly ash during photodegradation of RR45 dye. Science and Engineering of Composite Materials 2019; 26(1): 292-300. doi: 10.1515/secm-2019-0017.
27. Dastjerdi R, Montazer M. A review on the application of inorganic nano-structured materials in the modification of textiles: focus on anti-microbial properties. Colloids Surf B Biointerfaces 2010; 79(1): 5-18. doi: 10.1016/j. colsurfb.2010.03.029.

28. Alaton IA, Balcioglu IA, Bahnemann DW. Advanced oxidation of a reactive dyebath effluent: comparison of O3, $\mathrm{H} 2 \mathrm{O} 2 / \mathrm{UV}-\mathrm{C}$ and $\mathrm{TiO} 2 / \mathrm{UV}-\mathrm{A}$ processes. Water Res 2002; 36(5): 1143-54. doi: 10.1016/s0043-1354(01)00335-9.

29. Asiltürk M, Sayılkan F, Arpaç E. Effect of $\mathrm{Fe}^{3+}$ ion doping to $\mathrm{TiO}_{2}$ on the photocatalytic degradation of Malachite Green dye under UV and vis-irradiation. J Photochem Photobiol 2009; 203(1): 64-71. doi: 10.1016/j.jphotochem.2008.12.021.

30. Sayilkan F, Asiltürk M, Tatar P, Kiraz N, Arpaç E, Sayilkan H. Photocatalytic performance of Sn-doped TiO2 nanostructured mono and double layer thin films for Malachite Green dye degradation under UV and vislights. J Hazard Mater 2007; 144(1-2): 140-6. doi: 10.1016/j. jhazmat.2006.10.011.

31. Sayilkan F, Asilturk M, Tatar P, Kiraz N, Sener S, Arpac E, et al. Photocatalytic performance of Sn-doped TiO2 nanostructured thin films for photocatalytic degradation of malachite green dye under UV and VIS-lights. Materials Research Bulletin 2008; 43(1): 127-34. doi: 10.1016/j. materresbull.2007.02.012.

32. Saha S, Wang JM, Pal A. Nano silver impregnation on commercial $\mathrm{TiO}_{2}$ and a comparative photocatalytic account to degrade malachite green. Sep Purif Technol 2012; 89: 147-59. doi: 10.1016/j.seppur.2012.01.012.

33. Purkayastha MD, Datta J, Ray PP, Singh N, Darbha GK, Denrah S, et al. Modelling the photocatalytic behaviour of pn nickel-titanium oxide nanocomposite. Chem Eng Res Des 2020; 161: 82-94. doi: 10.1016/j.cherd.2020.06.027.

34. Rengifo-Herrera JA, Blanco MN, Pizzio LR. Photocatalytic bleaching of aqueous malachite green solutions by UV-A and blue-light-illuminated $\mathrm{TiO}_{2}$ spherical nanoparticles modified with tungstophosphoric acid. Applied Catalysis B: Environmental 2011; 110: 126-32. doi: 10.1016/j. apcatb.2011.08.034.

35. Yang J, Xu X, Liu Y, Gao Y, Chen H, Li H. Preparation of $\mathrm{SiO}_{2} @ \mathrm{TiO}_{2}$ composite nanosheets and their application in photocatalytic degradation of malachite green at emulsion interface. Colloids Surf A Physicochem Eng Asp 2019; 582: 123858. doi: 10.1016/j.colsurfa.2019.123858.

36. Tayade RJ, Surolia PK, Kulkarni RG, Jasra RV. Photocatalytic degradation of dyes and organic contaminants in water using nanocrystalline anatase and rutile $\mathrm{TiO}_{2}$. Sci Technol Adv Mater 2007; 8(6): 455-62. doi: 10.1016/j.stam.2007.05.006.

37. Du F, Sun L, Huang Z, Chen Z, Xu Z, Ruan G, et al. Electrospun reduced graphene oxide $/ \mathrm{TiO}_{2} /$ poly (acrylonitrile-co-maleic acid) composite nanofibers for efficient adsorption and photocatalytic removal of malachite green and leucomalachite green. Chemosphere 2020; 239: 124764. doi: 10.1016/j.chemosphere.2019.124764.

38. Jo WK, Tayade RJ. Facile photocatalytic reactor development using nano- $\mathrm{TiO}_{2}$ immobilized mosquito net and energy efficient UVLED for industrial dyes effluent treatment. J Environ Chem Eng 2016; 4(1): 319-27. doi: 10.1016/j.jece.2015.11.024.

39. Valentine JC, Pigott TD, Rothstein HR. How many studies do you need? A primer on statistical power for meta-analysis. J Educ Behav Stat 2010; 35(2): 215-47. doi: 10.3102/1076998609346961. 